\title{
Hydrogen storage in molecular compounds
}

\author{
Wendy L. Mao* ${ }^{*}$ and Ho-kwang Mao
}

*Department of the Geophysical Sciences, University of Chicago, Chicago, IL 60637; and ₹Geophysical Laboratory, Carnegie Institution of Washington, Washington, DC 20015

Contributed by Ho-kwang Mao, November 13, 2003

\begin{abstract}
At low temperature $(T)$ and high pressure $(P)$, gas molecules can be held in ice cages to form crystalline molecular compounds that may have application for energy storage. We synthesized a hydrogen clathrate hydrate, $\mathrm{H}_{2}\left(\mathrm{H}_{2} \mathrm{O}\right)_{2}$, that holds $50 \mathrm{~g}$ /liter hydrogen by volume or $5.3 \mathrm{wt} \%$. The clathrate, synthesized at 200-300 MPa and 240-249 K, can be preserved to ambient $P$ at $77 \mathrm{~K}$. The stored hydrogen is released when the clathrate is warmed to $140 \mathrm{~K}$ at ambient $P$. Low $T$ also stabilizes other molecular compounds containing large amounts of molecular hydrogen, although not to ambient $P$, e.g., the stability field for $\mathrm{H}_{2}\left(\mathrm{H}_{2} \mathrm{O}\right)$ filled ice $(11.2 \mathrm{wt} \%$ molecular hydrogen) is extended from 2,300 MPa at $300 \mathrm{~K}$ to 600 $\mathrm{MPa}$ at $190 \mathrm{~K}$, and that for $\left(\mathrm{H}_{2}\right)_{4} \mathrm{CH}_{4}$ (33.4 wt \% molecular hydrogen) is extended from $5,000 \mathrm{MPa}$ at $300 \mathrm{~K}$ to $200 \mathrm{MPa}$ at $77 \mathrm{~K}$. These unique characteristics show the potential of developing low- $T$ molecular crystalline compounds as a new means for hydrogen storage.
\end{abstract}

T he technology of using hydrogen as an environmentally clean and efficient fuel is an active research area worldwide $(1,2)$. Liquid hydrogen, which carries a high density of hydrogen (70 $\mathrm{g} /$ liter) and is currently the most commonly used form in prototype automobiles, is very energy intensive; up to $40 \%$ of the energy content must be spent to liquefy hydrogen at its very low condensation $T(20 \mathrm{~K})$. This low $T$ cannot be provided by practical and inexpensive cooling agents, e.g., liquid nitrogen ( $>77 \mathrm{~K}$ ); hence, the continuous boil-off of liquid hydrogen poses problems to on-board storage. Compressed hydrogen gas, the second most commonly used storage system, typically only holds $15 \mathrm{~g} /$ liter at $35 \mathrm{MPa}$. Higher pressures could hold higher hydrogen densities, but are complicated by safety concerns and logistical obstacles. Other storage methods, including molecular hydrogen adsorption on solids of large surface (e.g., carbon nanotubes) and bonded atomic hydrogen in hydrocarbons or in metal hydrides, have been developed extensively to address key issues of hydrogen content, $P-T$ conditions of synthesis and storage, and on-board hydrogen release (2).

Storing molecular hydrogen in the host of planetary ices (i.e., major constituents of icy satellites such as $\mathrm{H}_{2} \mathrm{O}, \mathrm{CH}_{4}, \mathrm{NH}_{3}, \mathrm{CO}_{2}$, etc.) and other larger molecules as a crystalline molecular compound may provide an attractive alternative method for hydrogen storage. A great variety of gas-ice molecular compounds have been synthesized by varying the $P-T$ conditions and the chemistry of the gases and ices (3-5), but systems involving molecular hydrogen have scarcely been studied. Two binaries, $\mathrm{H}_{2}-\mathrm{H}_{2} \mathrm{O}$ (6) and $\mathrm{H}_{2}-\mathrm{CH}_{4}$ (7), were previously investigated at high $P$ and $300 \mathrm{~K}$ for their planetary (8) and physical chemistry interest, resulting in the synthesis of a myriad of hydrogen-rich, crystalline compounds. They include $\mathrm{H}_{2}\left(\mathrm{H}_{2} \mathrm{O}\right)_{6}(23 \mathrm{~g} /$ liter hydrogen), which is stable above $700 \mathrm{MPa}(6) ; \mathrm{H}_{2}\left(\mathrm{H}_{2} \mathrm{O}\right)(110$ $\mathrm{g} /$ liter hydrogen), which is stable above 2,200 $\mathrm{MPa}$ (6); and $\mathrm{H}_{2}\left(\mathrm{CH}_{4}\right)_{2}, \mathrm{H}_{2}\left(\mathrm{CH}_{4}\right),\left(\mathrm{H}_{2}\right)_{2}\left(\mathrm{CH}_{4}\right)$, and $\left(\mathrm{H}_{2}\right)_{4}\left(\mathrm{CH}_{4}\right)$, which are stable between 4,500 and 8,000 MPa (7). These pressures are, however, too high; the hydrogen-bearing solids must be brought to near ambient $P$ to be of practical interest to hydrogen storage. Here we explore the moderately low $T(77-300 \mathrm{~K})$ region to search for new compounds capable of retaining a significant amount of hydrogen. Low $T$ hinders transition reversal and preserves high $P$ phases to near ambient $P(9)$.

\section{Experimental Methods}

We conducted low- $T$ studies on three hydrogen-ice systems: hydrogen-water $\left(\mathrm{H}_{2}-\mathrm{H}_{2} \mathrm{O}\right)$, hydrogen-methane $\left(\mathrm{H}_{2}-\mathrm{CH}_{4}\right)$, and hydrogen-octane $\left(\mathrm{H}_{2}-\mathrm{C}_{8} \mathrm{H}_{18}\right)$. Twelve experiments (nine on the $\mathrm{H}_{2}-\mathrm{H}_{2} \mathrm{O}$ system, two on the $\mathrm{H}_{2}-\mathrm{CH}_{4}$ system, and one on the $\mathrm{H}_{2}-\mathrm{C}_{8} \mathrm{H}_{18}$ system) were conducted in a diamond anvil cell (DAC) with $0.7-\mathrm{mm}$ diameter diamond culets. We used 0.25mm-thick gaskets made of T301 stainless steel or $\mathrm{BeCu}$ and drilled 0.25 - or $0.4-\mathrm{mm}$-diameter holes to contain the sample. For the $\mathrm{H}_{2}-\mathrm{H}_{2} \mathrm{O}$ and $\mathrm{H}_{2}-\mathrm{C}_{8} \mathrm{H}_{18}$ experiments, the sample chamber was partially filled ( $20-50 \%$ by volume) with distilled water and octane, respectively. Several small ruby grains were added for pressure calibration (10). The DAC was inserted in a gas pressure vessel to fill the remaining sample volume with compressed hydrogen gas (99.99\% purity) at $200 \mathrm{MPa}$. For the $\mathrm{H}_{2}-\mathrm{CH}_{4}$ experiments, a 1:1 mixture of $\mathrm{CH}_{4}$ and hydrogen gases was loaded at $200 \mathrm{MPa}$. After clamp-sealing the sample in gasket, the diamond cell was removed from the gas vessel and further compressed by using lever arms. The whole assembly was then introduced into a cryostat. The DAC was equipped with retracting springs to ensure smooth and complete pressure reduction in the cryostat. The systems were studied in situ at high $P$ and low $T$ by using optical microscopy, Raman spectroscopy, infrared spectroscopy (for the $\mathrm{H}_{2}-\mathrm{H}_{2} \mathrm{O}$ system only), $\mathrm{x}$-ray diffraction (for the $\mathrm{H}_{2}-\mathrm{H}_{2} \mathrm{O}$ and $\mathrm{H}_{2}-\mathrm{CH}_{4}$ systems), and neutron diffraction (for the $\mathrm{H}_{2}-\mathrm{H}_{2} \mathrm{O}$ system only).

\section{Experimental Results and Discussion}

The hydrogen-water system yielded two potential hydrogen storage materials, a hydrogen hydrate with classical sII structure (HH-sII) and a filled ice phase $\left(\mathrm{C}_{2}\right)(2,8)$. HH-sII, with molecular formula, $\mathrm{H}_{2}\left(\mathrm{H}_{2} \mathrm{O}\right)_{2}$ was synthesized at $250-600 \mathrm{MPa}$ and $249 \mathrm{~K}$, contains $50 \mathrm{~g} /$ liter hydrogen $(5.3$ mass $\%$ ), and was successfully quenched to ambient $P(0.1 \mathrm{MPa})$ at liquid nitrogen $T(77 \mathrm{~K})$, thus demonstrating the potential for hydrogen storage. In addition, this hydrogen clathrate may be important to our understanding of icy satellites of the outer solar system whose interior composition and $P-T$ conditions may overlap with those in the present study.

$\mathrm{HH}$-sII was studied for the $P-T$ range of $600-0.1 \mathrm{MPa}$ and $300-77 \mathrm{~K}$. Samples initially at $250-600 \mathrm{MPa}$ and $300 \mathrm{~K}$ were separated into two phases (Fig. 1a). Liquid water in region A and fluid hydrogen in region B have little mutual solubility as indicated by the absence of $\mathrm{OH}$ Raman vibration in the hydrogen region and very weak hydrogen molecular rotons and vibrons in the water region (11-13) (Fig. 1a). During isobaric cooling, the sample changed suddenly at $249 \mathrm{~K}$. A reaction rim grew between regions $\mathrm{A}$ and $\mathrm{B}$ while the main body of region $\mathrm{A}$ first darkened because of the infiltration of hydrogen and nucleation of a new phase, and then cleared up after the new phase completely took over region $\mathrm{A}$. The volume of region A increased $40 \%( \pm 2 \%)$ as the result of incorporation of hydrogen into $\mathrm{H}_{2} \mathrm{O}$ to form a hydrogen clathrate. As the water solidified into the clathrate, the

\footnotetext{
†To whom correspondence should be addressed at: Department of the Geophysical Sciences, University of Chicago, 5734 South Ellis Avenue, Chicago, IL 60637. E-mail: wmao@uchicago.edu.
}

() 2004 by The National Academy of Sciences of the USA 

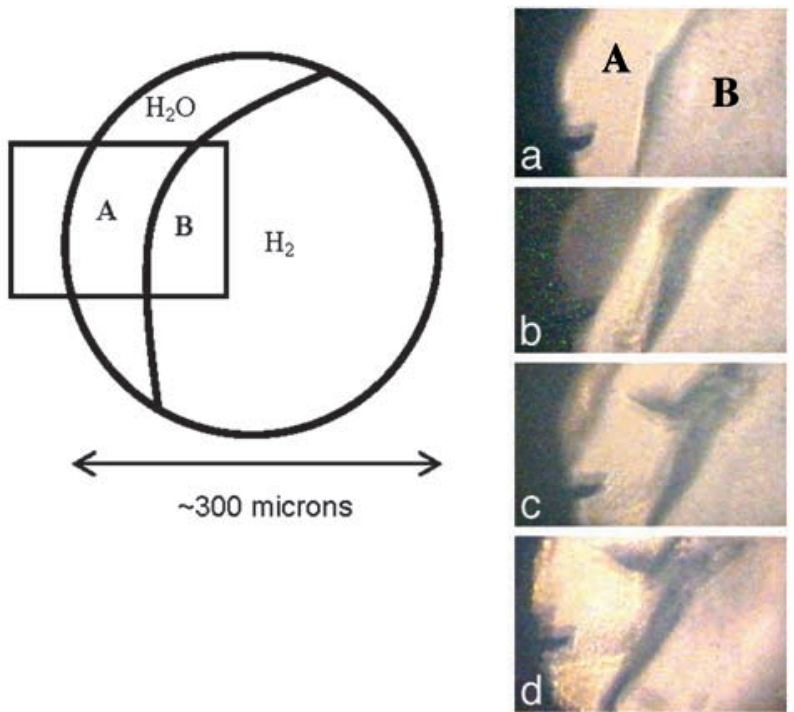

Fig. 1. Photomicrographs of hydrogen and water in the circular gasket hole at $300 \mathrm{MPa}$ as viewed through the diamond windows. (a) At $250 \mathrm{~K}$ before the formation of clathrate, the crescent-shaped water in region A was clearly separated from the hydrogen in region B. (b) Cooling down to $249 \mathrm{~K}$, a reaction zone of clathrate formed between hydrogen and water. The residual water darkened as clathrate nucleated. (c) The clathrate further grew at the expense of the water and hydrogen. A wedge-shaped crack developed during the volume expansion. (d) The reaction was completed after $30 \mathrm{~min}$ at $249 \mathrm{~K}$. At this point, all of the water had transformed completely into clathrate.

fluorescence peaks of ruby grains trapped in the clathrate broadened because of nonhydrostatic stress. The hydrostaticity and overall appearance of region $\mathrm{B}$, on the other hand, remained unchanged while its size decreased because of the incorporation of hydrogen into the growing hydrogen clathrate.

The formation and decomposition of the clathrate show large hysteresis. Similar to various phases of ices $(14,15)$, the clathrate can be quenched to ambient $P$ at low $T$. At $300 \mathrm{MPa}$, the clathrate was first observed at $249 \mathrm{~K}$ on cooling, whereas on subsequent warming at this $P$, the clathrate remained until reaching $280 \mathrm{~K}$, above which it began gradually decomposing into water and hydrogen. When the sample was isothermally decompressed from 300 to $0.1 \mathrm{MPa}$ at $77 \mathrm{~K}$, hydrogen in region $\mathrm{B}$ vanished, indicating the complete reduction of $P$ and escape of any unbonded hydrogen gas. Meanwhile, hydrogen vibrons and rotons in region A remained unchanged, indicating the successful storage of bonded hydrogen in the clathrate. The main, low-frequency vibron persisted on warming at a rate of 0.2 $\mathrm{K} / \mathrm{min}$ at ambient $P$, whereas the weak vibrons at higher frequency than $Q_{1}(1)$ of pure hydrogen gradually disappeared. Eventually, the clathrate disintegrated and released hydrogen at $140 \mathrm{~K}(16)$.

We synthesized a filled ice, $\mathrm{C}_{2}$, with molecular formula, $\mathrm{H}_{2}\left(\mathrm{H}_{2} \mathrm{O}\right)$, at $2,300 \mathrm{MPa}$ and $300 \mathrm{~K}$, cooled it isobarically to $77 \mathrm{~K}$, and then decompressed it isothermally to find the lower $P$ bound. $\mathrm{C}_{2}$ remained stable down to $500 \mathrm{MPa}$ at $77 \mathrm{~K}$ and decomposed at 400-300 $\mathrm{MPa}$. In another run, $\mathrm{C}_{2}$ was decompressed to 600 $\mathrm{MPa}$ at $77 \mathrm{~K}$ and warmed up isobarically. $\mathrm{C}_{2}$ remained up to 190 $\mathrm{K}$ (Fig. 2), decomposing on further warming.

In our exploration of the $\mathrm{H}_{2}-\mathrm{CH}_{4}$ system at low $T$, we found that the stability field of $\left(\mathrm{H}_{2}\right)_{4}\left(\mathrm{CH}_{4}\right), \mathrm{H} 4 \mathrm{M}$, which was small $(5,000-6,000 \mathrm{MPa})$ at $300 \mathrm{~K}(7)$, greatly expanded and became the only molecular compound between $\mathrm{H}_{2}$ and $\mathrm{CH}_{4}$ at $160 \mathrm{~K}$ and $1,000 \mathrm{MPa}$. H4M was identified by using Raman spectroscopy because it was found to be the only $\mathrm{H}_{2}-\mathrm{CH}_{4}$ compound having a hydrogen vibron peak at lower energy than the $Q_{1}(1)$ vibron

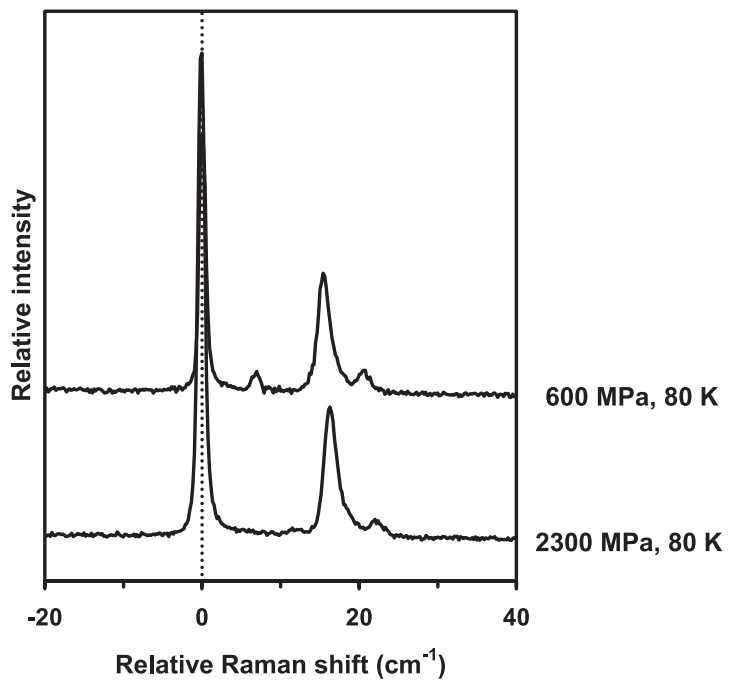

Fig. 2. Hydrogen vibron region in Raman spectra of $C_{2}$ filled ice. Spectra are shown relative to frequency of the $Q_{1}(1)$ peak in pure hydrogen at those conditions (indicated by the dashed line). Peaks at 0 relative Raman shift in the two spectra are due to unreacted hydrogen in sample. The peak at higher energy is due to $C_{2}$ filled ice.

(7). The low $P$ bound of $\mathrm{H} 4 \mathrm{M}$ was found to be $200 \mathrm{MPa}$ at $77 \mathrm{~K}$ (Fig. 3). H4M is extremely rich in molecular hydrogen containing $33.3 \mathrm{wt} \%$ molecular hydrogen, not counting the atomic hydrogen in $\mathrm{CH}_{4}$. Although this hydrogen-rich compounds have not yet been brought to ambient $P$, it is very encouraging that moderate cooling drastically reduces the $P$ at which hydrogen is stored by more than an order of magnitude and holds promise for other compounds in the $\mathrm{H}_{2}-\mathrm{CH}_{4}$ system.

To further explore hydrogen storage in another common fuel, the $\mathrm{H}_{2}-\mathrm{C}_{8} \mathrm{H}_{18}$ system was studied at $2,400 \mathrm{MPa}-0.1 \mathrm{MPa}$ and $300-100 \mathrm{~K}$ by using Raman spectroscopy. Over this range, no compounds were found. However, exploration of alkanes between methane and octane as well as other organic molecular

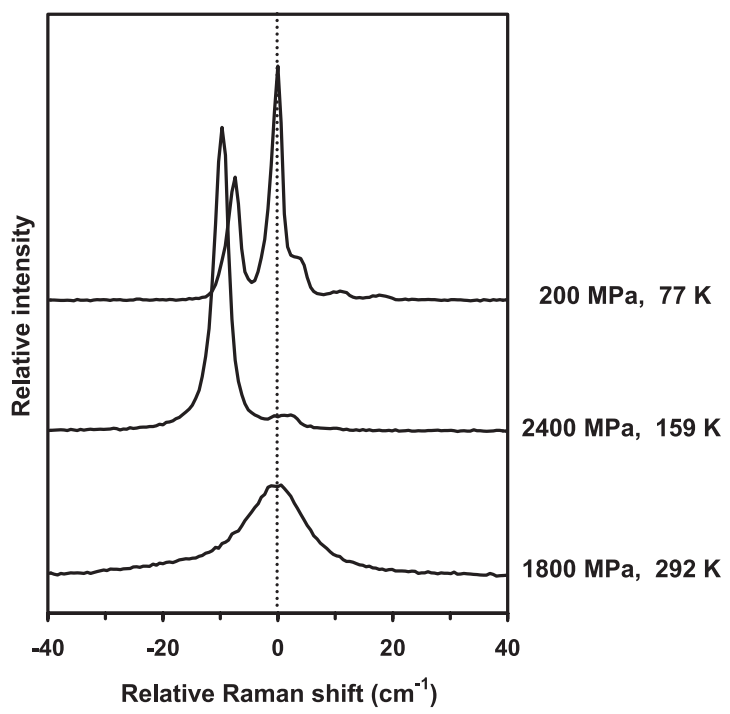

Fig. 3. Hydrogen vibron region in Raman spectra of H4M. Spectra are shown relative to frequency of the $Q_{1}(1)$ peak in pure hydrogen at those conditions (indicated by the dashed line). Peaks at 0 relative Raman shift in the two spectra are due to unreacted hydrogen in sample. The top two spectra show the presence of $\mathrm{H} 4 \mathrm{M}$, indicated by the peak at lower energy, which formed at $159 \mathrm{~K}$ and was retained down to $200 \mathrm{MPa}$ at liquid $\mathrm{N}_{2}$ temperature. 
Table 1. Comparison of molecular compounds with Department of Energy (DOE) hydrogen storage targets

\begin{tabular}{lccc} 
& $\mathrm{H}_{2}$ wt $\%$ & $\mathrm{~kW} \cdot \mathrm{h} / \mathrm{kg}$ & $\mathrm{kW} \cdot \mathrm{h} /$ liter \\
\hline $\mathrm{HH}-\mathrm{sll}, \mathrm{H}_{2}\left(\mathrm{H}_{2} \mathrm{O}\right)_{2}$ & 5.3 & 1.8 & 1.5 \\
$\mathrm{C}_{2}, \mathrm{H}_{2}\left(\mathrm{H}_{2} \mathrm{O}\right)$ & 11.2 & 3.7 & 3.5 \\
$\mathrm{H} 4 \mathrm{M},\left(\mathrm{H}_{2}\right)_{4}\left(\mathrm{CH}_{4}\right)$ & 33.4 & 11.1 & $\approx 10$ \\
2005 DOE target & 4.5 & 1.5 & 1.2 \\
2010 DOE target & 6 & 2 & 1.5 \\
2015 DOE target & 9 & 3 & 2.7 \\
\hline
\end{tabular}

hosts (e.g., unsaturated hydrocarbon) may produce suitable hydrogen storage materials.

\section{Prospects}

A practical hydrogen storage method must satisfy a number of requirements: $(i)$ high hydrogen content per unit mass, $(i i)$ high hydrogen content per unit volume, (iii) moderate synthesis $P$ (preferably $<400 \mathrm{MPa}$, the pressure that can be reached by a simple compressor), (iv) near ambient $P$ and moderate $T$ for storage, $(v)$ easy hydrogen release, and $(v i)$ environmentally friendly byproducts, if any. Storage of hydrogen in molecular compounds may provide an attractive alternative. As shown in Table 1, some molecular compounds hold large quantities of hydrogen that exceed Department of Energy targets for the years 2005-2015 in both $\mathrm{kW} \cdot \mathrm{h} / \mathrm{kg}$ and $\mathrm{kW} \cdot \mathrm{h} /$ liter. The $\mathrm{H}_{2} \mathrm{O}$ host molecules would be an environmentally friendly byproduct, and the $\mathrm{CH}_{4}$ host molecules could be used as a supplemental fuel. The main difficulty is that they require too high a pressure for synthesis and retention to be practical.

We explored a low-temperature route. In this method, hydrogen is retained and solidified by weak bonding to host molecules under moderate synthesis pressure $\left(P_{\mathrm{s}}\right)$ and temperature $\left(T_{\mathrm{s}}\right)$. The solid is cooled down to moderately low temperature $\left(T_{\mathrm{q}}\right)$, the pressure is released to the quench pressure $\left(P_{\mathrm{q}}\right)$, and the hydrogen-containing solid is retained. The stored hydrogen can be released by warming up toward a temperature $\left(T_{\mathrm{a}}\right)$ for final

1. Dresselhaus, M. S. \& Thomas, I. L. (2001) Nature 414, 332-337.

2. Schlapbach, L. \& Züttel, A. (2001) Nature 414, 353-358.

3. Chou, I.-M., Sharma, A., Burruss, R. C., Shu, J., Mao, H. K., Hemley, R. J., Goncharov, A. F., Stern, L. A. \& Kirby, S. H. (2000) Proc. Natl. Acad. Sci. USA 97, 13484-13487.

4. Loveday, J. S., Nelmes, R. J., Guthrie, M., Belmonte, S. A., Allan, D. R., Klug, D. D., Tse, J. S. \& Handa, Y. P. (2001) Nature 410, 661-663.

5. Hirai, H., Uchihara, Y., Fujihisa, H., Sakashita, M., Katoh, E., Aoki, K., Nagashima, K., Yamamoto, Y. \& Yagi, T. (2001) J. Chem. Phys. 115, 70667070.

6. Vos, W. L., Finger, L. W., Hemley, R. J. \& Mao, H. K. (1993) Phys. Rev. Lett. 71, 3150-3153.

7. Somayazulu, M. S., Finger, L. W., Hemley, R. J. \& Mao, H. K. (1996) Science 271, 1400-1402.

8. Stevenson, D. J. (1999) Nature 400, 32 (lett.).

9. Eremets, M. I., Hemley, R. J., Mao, H. K. \& Gregoryanz, E. (2001) Nature 411, $170-174$.

10. Zha, C.-S., Mao, H. K. \& Hemley, R. J. (2000) Proc. Natl. Acad. Sci. USA 97, 13494-13499. applications. As examples of this route for hydrogen storage, we report $\mathrm{H}_{2}\left(\mathrm{H}_{2} \mathrm{O}\right)_{2}$ clathrate, which contains a significant amount of hydrogen and is quenchable to ambient $P$ at moderately low $T$, and $\mathrm{H}_{2}\left(\mathrm{H}_{2} \mathrm{O}\right)$ filled ice and $\left(\mathrm{H}_{2}\right)_{4}\left(\mathrm{CH}_{4}\right)$ molecular compound, which contain higher amounts of hydrogen and can be quenched to moderate $P$ at low $T$. Ideally, the bonding to the ice host helps to stabilize molecular hydrogen in the crystalline compounds at moderately low $P-T$, yet is sufficiently weak for easy release. Other planetary ice or gas-ice systems are known to contain a great number of stable and metastable phases (14, 17-19), and new phases are still being discovered after decade of investigation $(3-5,20,21)$. By analogy, new compounds could be expected in the hydrogen-ice system by exploration of the multicomponent (including ternary compounds, e.g., $\mathrm{H}_{2} \mathrm{O}-\mathrm{CH}_{4}-\mathrm{H}_{2}$ ) system along different $P-T$ paths. Very large hysteresis and the pathdependent phase relationship at low $T$ open opportunities for metastable growth and stabilization of hydrogen-rich phases. Other avenues for future research exploration include investigation of larger guest molecules to stabilize the $\mathrm{H}_{2} \mathrm{O}$ framework structure of other clathrate and filled ice structures, and study of multiple occupation of $\mathrm{H}_{2}$ in cages of other structures.

In conclusion, the low-temperature path has greatly reduced the $P_{\mathrm{s}}$ and $P_{\mathrm{q}}$ of water and methane compounds. The field is in its infancy; only reconnaissance studies of the simplest compounds (water, methane, and octane) have been attempted. Exploration of compounds of other molecules in multidimensional $P-T-x$ space may lead to optimization of molecular compounds as a potential method of hydrogen storage. The diamond anvil cell (DAC), although not a production equipment, is a versatile tool for such explorations with in situ Raman, infrared, x-ray, and neutron probes.

We thank A. F. Goncharov, E. Gregoryanz, Q. Guo, J. Hu, J. Shu, M. Somayazulu, and V. V. Struzhkin for their help with the experiments, R. J. Hemley for discussions and comments, and the National Synchrotron Light Source at Brookhaven National Laboratory for synchrotron beam time. This work was supported by the National Science Foundation, the National Aeronautics and Space Administration, and the Department of Energy.

11. Hunter, J. E., Taylor, D. G. \& Strauss, H. L. (1992) J. Chem. Phys. 97, 50-59.

12. Strauss, H. L., Chen, Z. \& Loong, C.-K. (1994) J. Chem. Phys. 101, 7177-7180.

13. Chen, Z., Strauss, H. L. \& Loong, C.-K. (1999) J. Chem. Phys. 110, 7354-7358.

14. Kamb, B., Hamilton, W. C., LaPlaca, S. J. \& Prakash, A. (1971) J. Chem. Phys. 55, 1934-1945.

15. Klotz, S., Besson, J. M., Hamel, G., Nelmes, R. J., Loveday, J. S. \& Marshall, W. G. (1999) Nature 398, 681-684.

16. Mao, W. L., Mao, H. K., Goncharov, A. F., Struzhkin, V. V., Guo, Q., Hu, J., Shu, J., Hemley, R. J., Somayazulu, M. \& Zhao, Y. (2002) Science 297, 2247-2249.

17. Petrenko, V. F. \& Whitworth, R. W. (1999) Physics of Ice (Oxford Univ. Press, Oxford).

18. Tse, J. S. \& Klug, D. D. (1998) Phys. Rev. Lett. 81, 2466-2469.

19. Tse, J. S., Klug, D. D., Tulk, C. A., Swainson, I., Svensson, E. C., Loong, C.-K., Shpakov, V., Belosludov, V. R., Belosludov, R. V. \& Kawazoe, Y. (1999) Nature 400, 647-649.

20. Lobban, C., Finney, J. L. \& Kuhs, W. F. (1998) Nature 391, 268-270.

21. Chou, I.-M., Blank, J., Goncharov, A. F., Mao, H. K. \& Hemley, R. J. (1998) Science 281, 809-812. 